\title{
Explaining Regional Patterns of Violence in Times of Political Struggle: The Case of the 2005 Parliamentary Election in Afghanistan*
}

\author{
COSIMA MEYER*
}

University of Mannheim/Graduate School of Economic and Social Sciences, Germany

\section{DENNIS HAMMERSCHMIDT**}

University of Mannheim/Graduate School of Economic and Social Sciences, Germany

One in three elections happens in times of conflict. ${ }^{1}$ Although this share is substantial, research has not yet systematically analyzed whether and how elections affect patterns of violence during conflict. Elections mark strategically important events. In the context of civil conflict, we expect them to trigger specific patterns of violence. We presume that rivaling parties use elections strategically to reveal the other party's weaknesses and/or to garner support. ${ }^{2}$ The research focus on the strategic role of pre-electoral violence emerged only recently, but has, to the best of our knowledge, not yet been studied in the context of election-related patterns of violence during civil wars. The case of Afghanistan in the 2018 election portrays the necessity of this focus quite vividly. The country witnessed an increase in attacks by non-state armed actors with the specific aim to delegitimize the government. ${ }^{3}$ Besides a mere increase in violence during the pre-election phase, we expect to see a second pattern of violence: a concentration of violence in specific, strategically important areas. Those areas can be regional strongholds of the actors, such as the capital or rebel-controlled areas.

1 Flores 2014.

2 See for example Höglund 2005.

3 Beahm 2018.

* This work was supported by the University of Mannheim's Graduate School of Economic and Social Sciences funded by the German Research Foundation.

**cosima.meyer@uni-manheim.de

****dhammers@mail.uni-mannheim.de 
To illustrate our assumptions, we consider the case of Afghanistan in 2005. As the first parliamentary election since 1988, it marks an important milestone in the democratization process, at a time when the strongest non-state armed actor, the Taliban, increasingly regained control of particular regions. Our map displays these areas in light grey and plots the share of violence - both for state-based and one-sided violence - as a percentage of the accumulated violence of the past 12 months of the date of the attack in red. ${ }^{4}$ Starting 180 days prior to the election day ${ }^{5}$, we observe an increase in violence the closer the election gets. Most importantly, this increase is clustered in the stronghold regions of the Taliban as time proceeds. Especially when we zoom in on the last 30 days before the election, our map illustrates that the large majority of attacks happen in the most important areas for the Taliban: Helmand, Zabul, and Kandahar. ${ }^{6}$ These districts were alsotraditionally the Taliban's strongholds where they ran most of their lucrative narcotics trade.

Our map thus highlights that there are two important spatial dimensions that explain the link between elections and violence. On the one hand, time plays a role where closer to the election, violence increases. On the other hand, this increase in violence is regionally clustered in areas that are controlled by a non-state armed actor. As a result, we find support for our assumption that an election can trigger specific regional patterns of violence and we expect to observe similar findings in other countries.

4 We retrieve our data for the base map from the GADM database (Hijmans 2018), for violence from the UCDP GED dataset (2018), and information on Taliban strongholds comes from Stanford University (2016).

5 We retrieve the information on the election date from the NELDA dataset (Hyde und Marinov 2015).

6 Stanford University 2016. 

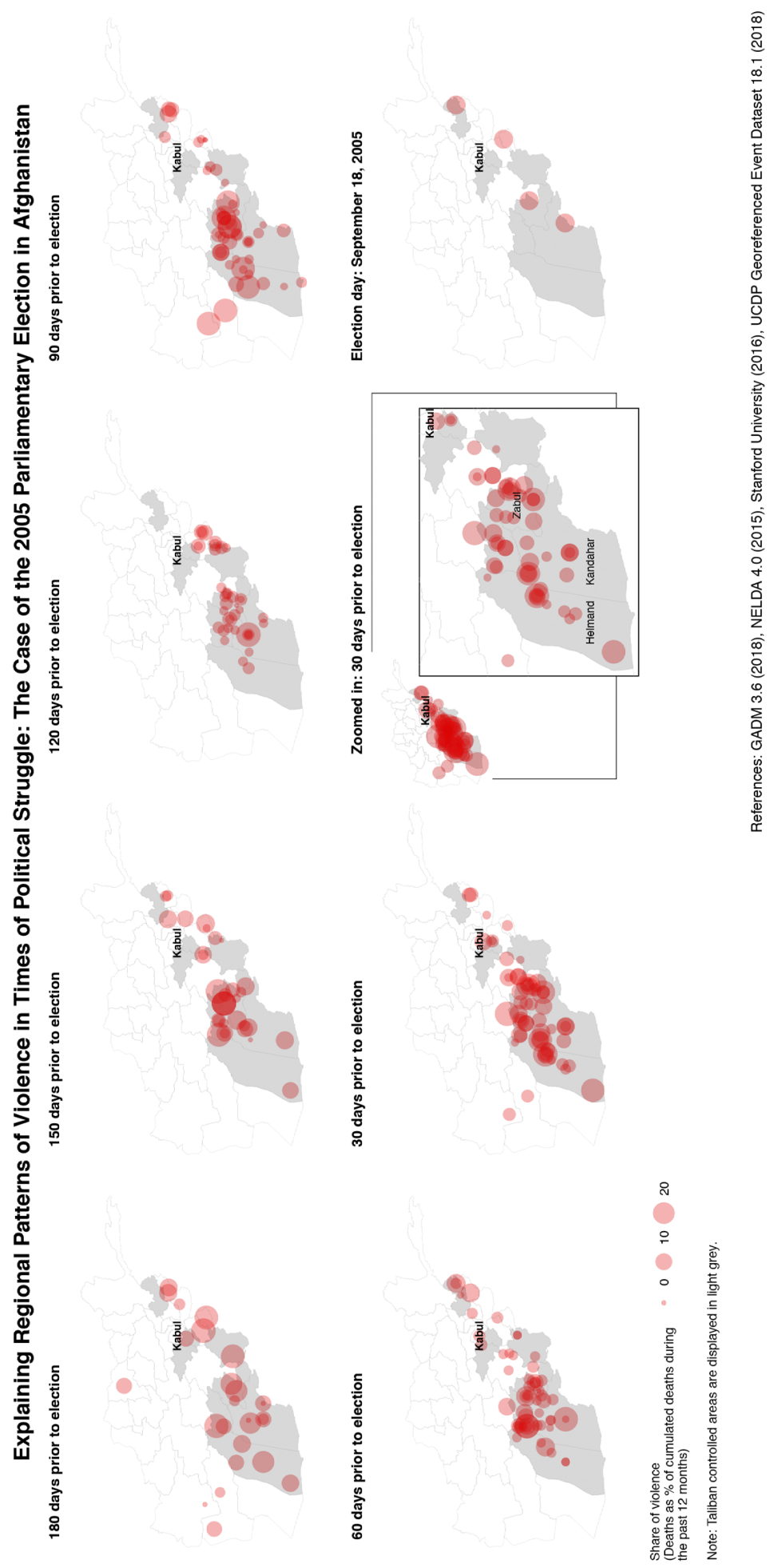